\title{
A Review of Research on Whistle-Blowing
}

\section{Li Chen}

School of Management, Jinan University, Guangzhou, China

Email:cl-chenli@foxmail.com

How to cite this paper: Chen, L. (2019) A Review of Research on Whistle-Blowing. American Journal of Industrial and Business Management, 9, 295-305. https://doi.org/10.4236/ajibm.2019.92019

Received: January 18, 2019

Accepted: February 18, 2019

Published: February 21, 2019

Copyright $\odot 2019$ by author(s) and Scientific Research Publishing Inc. This work is licensed under the Creative Commons Attribution International License (CC BY 4.0).

http://creativecommons.org/licenses/by/4.0/

\begin{abstract}
The whistle-blowing behavior in the organization is an employee's whistle-blowing on the illegal, destructive rules and unethical behaviors in the workplace, and is an effective mechanism to timely correct non-ethical behaviors in the organization. The article reviews the research origin, concept and measurement methods of whistle-blowing behaviors, discusses the decision-making process of whistle-blowing behavior from different theoretical perspectives, and systematically sorts out the influencing factors and generating mechanisms of whistle-blowing intention or behavior from multiple levels. Proposing future research should focus on issues such as localized whistle-blowing behavior, the impact of different context variables, and longitudinal research on whistle-blowing behavior.
\end{abstract}

\section{Keywords}

Whistle-Blowing Intention, Whistle-Blowing, Whistle-Blowing

Decision-Making

\section{Introduction}

In recent years, organizational moral anomie has emerged in an endless stream, and moral and ethical issues have become the focus of attention in the practical and theoretical circles. In the eighteenth century, British politician Burke famously said: "The only necessary condition for evil to win is that the good guys stand by", from the opposite side, pointing out the key role of whistle-blowing in stopping wrong doing, a lot of practice. It also proves that whistle-blowing behavior in an organization is one of the effective ethical management tools of an organization. There are often eye-catching reports in China's media reports, and the government is also strengthening anti-corruption efforts. Therefore, it is of great practical significance to carry out research on whistle-blowing behaviors in organizations. 
Western scholars in the fields of law, ethics and organization began to study the whistle-blowing behavior from the middle of the last century. Among them, the research on whistle-blowing behavior in the organization has achieved relatively fruitful results, but the relevant research in China is still relatively lacking. This paper sorts out the research on whistle-blowing behaviors in the organization (hereinafter referred to as whistle-blowing) and proposes possible future research directions.

\section{Concept and Measurement of Whistle-Blowing}

\subsection{Concept of Whistle-Blowing}

Whistle-blowing refers to the act of an existing or former member of an organization discovering an illegal, unethical, or irregular behavior in an organization and whistle-blowing to an individual or organization that may affect the behavior [1]. Whistle-blowing behavior includes two methods: one is internal whistle-blowing, which points to the superior leadership and management within the organization to report problems; the other is external whistle-blowing, pointing to whistle-blowing issues by government agencies, the media or professional organizations. This definition has been widely recognized by researchers and is quoted to this day. The whistle-blowing behavior has been defined by scholars as prosocial, off-character, and organizational citizenship behaviors. The three views agree that: 1) the basic motivation for whistle-blowing behavior is to prevent misconduct, and it is a positive behavior that hopes to benefit society, organization, and others. 2) whistle-blowing behavior is self-reflective, independent, and not subject to mandatory requirements.

\subsection{Measurement of Whistle-Blowing}

Miceli et al. (2009) argued that whistle-blowing behavior does not occur often compared to other behaviors. At the same time, it is difficult to observe because most of them are conducted through confidential hot-lines or anonymous letters [2]. Most existing studies use two types of methods to measure whistle-blowing behavior. First, the actual whistle-blowing behavior is measured. The respondent selects the dichotomous variable according to the recall, such as "Is it reported to the internal superiors after the discovery of the unethical behavior?" The second is to solve the difficulty of measuring the actual whistle-blowing behavior by measuring the intention to whistle-blowing. For example, the scale developed by Park et al. (2005) uses three items to measure internal whistle-blowing intention, external whistle-blowing intention and non-whistle-blowing intention. Questions such as "If I find misconduct in the workplace, I will whistle-blowing this to my superior." [3].

For complex whistle-blowing behavior, existing measurement tools are simple, inconsistent, and less stringent. Whether it is possible to conduct a subdivision of the structural dimension according to different motives, purposes, processes or outcomes remains to be explored by scholars; Secondly, the whis- 
tle-blowing behavior is a highly sensitive topic, and the self-whistle-blowing scale will inevitably lead to social deviation bias and recall bias; Moreover, since individuals generally overestimate their moral tendencies, an individual's intention to report does not necessarily mean that actual whistle-blowing behavior will occur. Meta-analytic studies have found that the relationship between some variables and the intention to report is significantly stronger than the relationship with the actual report. These problems are one of the reasons why the current empirical research conclusions are inconsistent, difficult to compare and integrate. In the future, it is necessary to improve the research methods, combined with the research objectives, objects and situations, using a series of research or mixed research design, combined with the use of multiple methods in qualitative and quantitative research to appropriately supplement the deficiencies of a single research method.

\section{Decision-Making Process of Whistle-Blowing}

Individuals observe that misconduct is not the same as when they detect an emergency (such as a fire or a bloody event), and they have sufficient time to make decisions in the former situation. Studies have developed a whistle-blowing decision process model from the perspective of prosocial organizational behavior, ethical behavior, social information processing, and collection theory (see Table 1).

\subsection{Prosocial Organizational Behavior (POB) Model}

Dozier (1985) used the POB model to describe the whistle-blowing decision process: 1) perception of misconduct, i.e. whether it has been reported or corrected;

Table 1. Whistle-blowing decision process.

\begin{tabular}{|c|c|c|c|c|}
\hline $\begin{array}{c}\text { Theoretical } \\
\text { model }\end{array}$ & The first stage & $\begin{array}{l}\text { The second } \\
\text { stage }\end{array}$ & The third stage & The fourth stage \\
\hline POB model & $\begin{array}{l}\text { Perception of } \\
\text { misconduct; } \\
\text { whether } \\
\text { misconduct has } \\
\text { been reported or } \\
\text { corrected }\end{array}$ & $\begin{array}{l}\text { Analyze the } \\
\text { signals } \\
\text { transmitted by } \\
\text { misconduct and } \\
\text { the extent of the } \\
\text { damage caused }\end{array}$ & $\begin{array}{l}\text { Judging } \\
\text { whistle-blowing } \\
\text { responsibilities; } \\
\text { the possibility of } \\
\text { whistle-blowing } \\
\text { success; } \\
\text { assessing } \\
\text { benefit-cost }\end{array}$ & $\begin{array}{c}\text { Generate } \\
\text { intention or } \\
\text { behavior to } \\
\text { whistle-blowing }\end{array}$ \\
\hline EB model & $\begin{array}{c}\text { Aware of } \\
\text { unethical } \\
\text { behavior, the } \\
\text { interests of one } \\
\text { party have been } \\
\text { harmed }\end{array}$ & $\begin{array}{c}\text { Determining } \\
\text { whether } \\
\text { whistle-blowing } \\
\text { is an ideal } \\
\text { moral choice }\end{array}$ & $\begin{array}{c}\text { Assess the } \\
\text { extent of ethical } \\
\text { values, } \\
\text { accountability } \\
\text { and ethical } \\
\text { commitment }\end{array}$ & Ethical choice \\
\hline SIP model & $\begin{array}{l}\text { Observed } \\
\text { misconduct; } \\
\text { economic } \\
\text { rationality }\end{array}$ & $\begin{array}{c}\text { Responsibility } \\
\text { attribution }\end{array}$ & $\begin{array}{l}\text { Responsibility } \\
\text { judgment, } \\
\text { emotional } \\
\text { change }\end{array}$ & $\begin{array}{c}\text { Emotional } \\
\text { change makes a } \\
\text { decision }\end{array}$ \\
\hline
\end{tabular}


2) analysis of the signal transmitted by the misconduct and the extent of the harm caused, such as the presence of misconduct indicates The default attitude of the manager? What is the level of psychological damage caused by employees? 3) to determine whether they have the responsibility and ability to whistle-blowing and prevent misconduct, while assessing the expected benefits and costs of whistle-blowing actions; 4) generate intention and behavior [4]. The POB model follows an economically rational decision-making process that considers the "benefit-cost" of whistle-blowing actions. The observer will only take action when the expected benefit is greater than the cost. Therefore, the POB model is a result-oriented utility decision-making model. Empirical studies based on the POB model are the most common. The researchers verified the influence of different independent variables on whistle-blowing decisions, and explained that the internal mechanism of action is the individual or contextual factors acting on the observer's psychological cognition, which affects the whistle-blowing decision by affecting the benefit-cost analysis. For example, Keil et al. (2010) found that positive organizational climate and boss trust promoted whistle-blowing intention through the intermediary role of benefit-cost analysis [5]; Gaudine et al. (2001) found that people with positive emotions have positive bias toward the assessment of whistle-blowing results. Therefore, positive emotions promote the intention to whistle-blowing [6].

\subsection{Ethical Behavior (EB) Model}

Trevino et al. (2006) pointed out that whistle-blowing behavior is a high-ethical organizational behavior. The ethical behavior model describes the whistle-blowing decision-making process as follows: 1) ethical perception, which means that the occurrence of misconduct and the interests of one party are damaged; 2) ethical judgment, i.e. Thinking whether whistle-blowing is an ideal moral choice; 3 ) ethical incentives, that is, assessing the importance of moral values relative to other values, the degree of responsibility and ethical commitment; 4) ethical choices, that is, making whistle-blowing decisions [7]. Unlike the POB model, the EB model emphasizes the psychological process of moral cognition, and the observer decides whether to make a report by moral judgment. This makes the EB model and the POB model very different in economic rationality, and the $\mathrm{EB}$ model is biased towards the moral decision-making model. However, the EB model does not deny the interference of economic rationality. For example, Zhang et al. (2009) found that internal control points or positive affects positively regulate the relationship between moral judgment and whistle-blowing intention [8].

\subsection{Social Information Processing (SIP) Model}

Gundlach et al. (2003) established a SIP model based on the POB model, which means that individuals make whistle-blowing decisions by interpreting misconduct and information of actors. The process is: 1) Observing inappropriate be- 
havior; 2) Attribution (referring to the cause of misconduct events) and economic rational processes. The actor's impression management affects these two parallel processes; 3) responsibility judgment and emotional change process (such as fear, understanding, anger, etc.); 4) making report decisions [9]. The SIP model interprets the whistle-blowing decision process from a more systematic cognitive perspective. Specifically, the SIP model not only recognizes economic rationality as an important stage of the decision-making process, but also emphasizes the importance of the attribution process. The SIP model states that attribution and economic rationality are biased by the impression management of actors (such as finding excuses, apologies, intimidation, etc.). The SIP model integrates the emotional response process of the observer into the decision-making process, pointing out that attribution, responsibility judgment and economic rationality will cause the observer to have emotional changes and thus influence the whistle-blowing behavior. The SIP model shifts the researcher's thinking into attention to misconduct and actors. Bhal et al. (2011), Robinson et al. (2011), and Michael et al. (2008) empirically studied the moral strength of misconduct [10], type [11], evidence [12] and other impacts on whistle-blowing decisions. For example, Bhal (2011) found that the moral intensity of unethical behavioral events positively regulates the relationship between ethical leadership, leadership-member exchange quality and whistle-blowing intention [10].

\section{Influencing Factors of Whistle-Blowing Intention and Behavior}

This paper sorts out the influencing factors of employee's intention and behavior, and believes that the factors affecting employee whistle-blowing include individual factors, organizational factors and national factors. Details are as follows:

\subsection{Individual Factor}

- The Demographic characteristics. Some scholars use the theory of power to explain the influence of demographic characteristics. They think that demographic characteristics represent the power of ordinary meaning, and power influences the whistle-blowing results, which in turn affects the whistle-blowing behavior. However, the research conclusions obtained by empirical research are not consistent. For example, Lee et al. (2004) found that men, seniors, and long-term tenants are more likely to whistle-blowing [13]. Mesmer-Magnus et al. (2005) found that women were more likely to whistle-blowing, and older people were negatively correlated with internal whistle-blowing and their tenure was not related to internal whistle-blowing [14]. It can be explained that the demographic characteristics are only the external characteristics of the individual, and their effects are interfered by the context variables and do not have a stable predictive ability.

- Personality and emotion. The influence of individual intrinsic characteristics such as personality or emotion on whistle-blowing intention and behavior 
has been unanimously recognized by recent research. For example, Bjorkelo et al. (2010) found that extroversion, low affinity, and dominance in the "Big Five" personality promoted whistle-blowing behavior [15]; MacNab (2008) found that high self-efficacy enhances whistle-blowing intention [16]; Michael (2008) demonstrates that situation-specific leverage (an informal power that acts in a specific context, related to expertise, authority, and interpersonal relationships) positively affects actual whistle-blowing behavior [12]. Gaudine (2001) found that people with positive emotions are more willing to help others, protect organizations and make recommendations that are beneficial to the organization. At the same time, the perception and evaluation of the whistle-blowing results will have a positive bias, thus promoting the intention to whistle-blowing [6].

- Job role. Characteristics such as role responsibility and supervisor identity represent the formal power of the individual in the organization and symbolize the "legality" of the behavior. Miceli (2002) found that role responsibilities and supervisor status influence whistle-blowing intention or behavior [17]. This is because when the role responsibilities clearly state that the individual has the responsibility to monitor and correct misconduct in the organization, the observer will do his duty and believe that the whistle-blowing action will be treated correctly.

- Perception and attitude. Trevino (2001) found that when employees perceive organizational justice and have a clear ethical plan, they are more willing to whistle-blowing management issues, and channel fairness promotes employees' intention to whistle-blowing and actual whistle-blowing behavior [18]. In the latest research, some scholars stand on the basis of economic rationality and regard employees as "rational people" to analyze the "benefit-cost" of whistle-blowing behavior. Alleyne (2017) believes that there are significant negative correlations between the whistle-blowing intention and the costs of whistle-blowing such as retaliation, threats, and damages, and that the auditor's perceived cost is higher. The lower the intention to whistle-blowing [19]. Dalton (2013) pointed out that Machiavellianism indirectly affects whistle-blowing intention through perceived costs and perceived benefits [20]. Gao (2014) found that factors such as whistle-blowing channels and the power status of the wrong person indirectly affect the intention to whistle-blowing through perceived cost, perceived severity, and perceived responsibility [21]. Keil (2010) pointed out that the trust of the boss, whistle-blowing anonymity, responsibility and so on all influence the whistle-blowing decision by affecting the benefit-cost [5]. It can be seen that most of the individual factors indirectly affect the intention to whistle-blowing by influencing the cost-benefit perceived by the whistle-blowing behavior.

\subsection{Organizational Situational Factors}

- Ethical culture and ethical atmosphere. Trevino (2006) believes that ethical culture makes ethical decisions by influencing employees' psychological per- 
ception structure and enabling employees to understand the shared values and goals of the organization. Zhang et al. (2009) found that positive ethical culture strengthens the legitimacy and collective norms of ethical behavior, affects the expected effectiveness of employees in whistle-blowing, and thus promotes the intention to whistle-blowing [8]. Kaptein (2010) found that negative negative ethical culture hinders the generation of intention to whistle-blowing [22].

- The whistle-blowing system. Lewis et al. (2007) pointed out that the establishment of a clearly visible whistle-blowing system can help to alleviate the concerns of observers and promote the intention to whistle-blowing and the realization of behavior [23]. The Stansburry (2009) survey found that most companies in the European sample provide confidentiality guarantees and anonymous whistle-blowing procedures, with nearly half of the companies providing hotline services; 95\% of North American multinational companies have dedicated whistle-blowing hotline services [24]. Lee et al. (2013) found that organizations supporting whistle-blowings, allowing anonymous whistle-blowing, the number of external auditors in the audit committee, and the extent of centralized shareholdings are positively related to employees' intention to whistle-blowing, and the establishment of a dedicated whistle-blowing hotline is one of the most effective whistle-blowing systems [25].

\subsection{National Factor}

- National laws and regulations. In recent years, countries have introduced laws and regulations aimed at protecting and motivating whistle-blowers. Lewis (2007) survey results show that whistle-blowing laws and regulations have a significant role in promoting whistle-blowing behavior [23]. However, Vandekerckhove et al. (2011) pointed out that there is a general lack of guidance on the methods of managing whistle-blowing behaviors in existing laws and regulations, failing to adequately provide incentives for bonuses, and failing to emphasize the role responsibility requirements of key players in whistle-blowing, and lack of mode of operation for monitoring and checking whistle-blowing [26]. The improvement of national whistle-blowing laws has important reference significance for the establishment of whistle-blowing laws in China.

- National culture. The study of the influence of national culture on whistle-blowing behavior can be summarized into the following three categories: The first category is to compare the ways or the influencing factors of whistle-blowing behaviors in cross-cultural contexts. For example, Park et al. (2008) found that college students in Korea, Turkey and the United Kingdom tend to formally, anonymously and internally whistle-blowing [27]; Trongmateerut (2013) pointed out that the subjective norms of whistle-blowing of college students in Thailand and the United States are different, but they all affect whistle-blowing. Will, while the former is more closely related [28]; the 
second is to examine the influence of cultural dimensions. For example, Park (2005)'s research on Korean civil servants found that the "father as a subclass" culture in Confucian ethics hinders the intention to whistle-blowing, while the "following a wife" culture promotes intention to whistle-blowing; horizontal collectivism promotes whistle-blowing intention, while vertical collectivism There is no influence on the intention to whistle-blowing [3]; the third category is to explore the whistle-blowing mechanism in a specific cultural context. For example, Skivennes (2010) found that most Norwegian public sector employees whistle-blowing their behavior when they observe unethical behavior, and they are effective. Rarely retaliated by organizations, which is quite different from existing research findings. The research proves that the communication culture, collective arrangement and legal awareness of Norwegian organizations are the main reasons for promoting whistle-blowing behavior [29]. Zhang et al. (2009) found that the emergence of internal whistle-blowing intention in the Chinese context was influenced by organizational ethical culture and positive emotions [8].

The following is a summary of the factors affecting whistle-blowing (see Table 2).

\section{Future Progress}

\subsection{Conduct Localized Whistle-Blowing Research}

China's legal, cultural and economic environment determines the unique background of whistle-blowing behavior. For example, there is no specific whistle-blowing law in China, and potential whistle-blowers lack security and incentives. The values of Chinese culture, moral awareness, and the identification of unethical behavior may differ from those of Western countries. The cultural characteristics of "harmony" thinking, collectivism, high power distance, and high uncertainty avoidance are in opposition to whistle-blowing behaviors that challenge authority, destroy interpersonal relationships, risk and "unfaithfulness"; Oversupply in the job market makes it difficult for potential whistle-blowers to bear retaliation results such as career risks. In this context, existing research results from Western countries may not be fully suitable for China's localized whistle-blowing behavior research. Therefore, carrying out research on whistle-blowing behavior in China's context is an important and key future research direction.

\subsection{Differentiate the Impact of Specific Context Variables}

First, explore the impact of different types of industries, especially those with non-ethical issues such as food, medical care, and finance that frequently occur and are highly harmful. Exploring the mechanisms and outcomes of whistle-blowing behaviors in these industries and designing whistle-blowing behavior induction mechanisms are of great significance for guiding practice. Secondly, the existing research has not fully paid attention to the impact of ethical 
Table 2. Influencing factors of whistle-blowing.

\begin{tabular}{|c|c|c|c|c|c|}
\hline $\begin{array}{l}\text { Representative } \\
\text { scholar }\end{array}$ & Journal & $\begin{array}{c}\text { Year of } \\
\text { publication }\end{array}$ & $\begin{array}{l}\text { Individual } \\
\text { factor }\end{array}$ & $\begin{array}{l}\text { Organizational } \\
\text { factor }\end{array}$ & $\begin{array}{c}\text { National } \\
\text { factor }\end{array}$ \\
\hline Alleyne & $\begin{array}{c}\text { Meditari } \\
\text { Accountancy } \\
\text { Research }\end{array}$ & 2017 & $\sqrt{ }$ & - & - \\
\hline Gao & $\begin{array}{c}\text { Journal of Business } \\
\text { Ethics }\end{array}$ & 2015 & $\sqrt{ }$ & - & - \\
\hline Trongmateerut & $\begin{array}{c}\text { Journal of Business } \\
\text { Ethics }\end{array}$ & 2013 & - & - & $\sqrt{ }$ \\
\hline Lee & $\begin{array}{c}\text { Journal of Business } \\
\text { Ethics }\end{array}$ & 2013 & - & - & $\sqrt{ }$ \\
\hline Kaptein & $\begin{array}{c}\text { Journal of Business } \\
\text { Ethics }\end{array}$ & 2010 & - & $\sqrt{ }$ & - \\
\hline Bjorkelo & $\begin{array}{c}\text { Journal of } \\
\text { Occupational \& } \\
\text { Organizational } \\
\text { Psychology, }\end{array}$ & 2010 & - & $\sqrt{ }$ & - \\
\hline Skivenes & Human Relations & 2010 & - & - & $\sqrt{ }$ \\
\hline Zhang & $\begin{array}{c}\text { Journal of Business } \\
\text { Ethics }\end{array}$ & 2009 & - & $\sqrt{ }$ & - \\
\hline Trevino & $\begin{array}{c}\text { Journal of } \\
\text { Management, }\end{array}$ & 2006 & - & $\sqrt{ }$ & - \\
\hline Lee & Human Relations & 2004 & $\sqrt{ }$ & - & - \\
\hline Gaudine & $\begin{array}{c}\text { Journal of Business } \\
\text { Ethics }\end{array}$ & 2001 & $\sqrt{ }$ & - & - \\
\hline
\end{tabular}

incentive policies and human resource management practices as organizational situations. It is necessary to explore how to combine ethical incentive policies with human resource management systems to stimulate and induce whistle-blowing behaviors. Finally, strengthen the test of the characteristics of unethical actors and the impact of impression management on the observers; and explore the impact of the internal and external characteristics of the recipient's power, attitude, mood, and intention on the observer's whistle-blowing decisions.

\subsection{Longitudinal Study of Whistle-Blowing}

Most of the existing research is cross-sectional research, even for longitudinal studies, the time span is very short. Although this kind of linear measurement has certain predictive power, it is not clear that the whistle-blowing behavior is a continuous process and its subsequent changes, especially the reporter's cognition and changes in emotions and behaviors. In the future, longitudinal research is needed to further explore the different stages of the whistle-blowing and decision-making process, and to further clarify the persistence of whistle-blowing behaviors and the psychological changes of reporters. 


\section{Conflicts of Interest}

The author declares no conflicts of interest regarding the publication of this paper.

\section{References}

[1] Near, J.P. and Miceli, M.P. (1985) Organizational Dissidence: The Case of Whistle-Blowing. Journal of Business Ethics, 4, 1-16. https://doi.org/10.1007/BF00382668

[2] Morrison, E.W. (2009) Marcia P. Miceli, Janet P. Near, and Terry Morehead Dworkin: Whistle-Blowing in Organizations. Administrative Science Quarterly, 54, 344-346. https://doi.org/10.2189/asqu.2009.54.2.344

[3] Park, H., Rehg, M.T. and Lee, D. (2005) The Influence of Confucian Ethics and Collectivism on Whistleblowing Intentions: A Study of South Korean Public Employees. Journal of Business Ethics, 58, 387-403. https://doi.org/10.1007/s10551-004-5366-0

[4] Dozier, J.B. and Miceli, M.P. (1985) Potential Predictors of Whistle-Blowing: A Prosocial Behavior Perspective. Academy of Management Review, 10, 823-836. https://doi.org/10.5465/amr.1985.4279105

[5] Keil, M., Tiwana, A., Sainsbury, R., et al. (2010). Toward a Theory of Whistleblowing Intentions: A Benefit-to-Cost Differential Perspective. Decision Sciences, 41, 787-812. https://doi.org/10.1111/j.1540-5915.2010.00288.x

[6] Gaudine, A. and Thorne, L. (2001) Emotion and Ethical Decision-Making in Organizations. Journal of Business Ethics, 31, 175-187. https://doi.org/10.1023/A:1010711413444

[7] Trevino, L.K., Weaver, G.R. and Reynolds, S.J. (2006) Behavioral Ethics in Organizations: A Review. Journal of Management, 32, 951-990. https://doi.org/10.1177/0149206306294258

[8] Zhang, J., Chiu, R. and Wei, L. (2009) Decision-Making Process of Internal Whistleblowing Behavior in China: Empirical Evidence and Implications. Journal of Business Ethics, 88, 25-41. https://doi.org/10.1007/s10551-008-9831-z

[9] Gundlach, M.J. and Martinko, D.M.J. (2003) The Decision to Blow the Whistle: A Social Information Processing Framework. The Academy of Management Review, 28, 107-123. https://doi.org/10.5465/amr.2003.8925239

[10] Dadhich, B.A. (2011) Impact of Ethical Leadership and Leader-Member Exchange on Whistle Blowing: The Moderating Impact of the Moral Intensity of the Issue. Journal of Business Ethics, 103, 485-496. https://doi.org/10.1007/s10551-011-0876-Z

[11] Robinson, S.N., Robertson, J.C. and Curtis, M.B. (2012) The Effects of Contextual and Wrongdoing Attributes on Organizational Employees' Whistleblowing Intentions Following Fraud. Journal of Business Ethics, 106, 213-227. https://doi.org/10.1007/s10551-011-0990-y

[12] Rehg, M.T., Miceli, M.P., Near, J.P. and Van Scotter, J.R. (2008) Antecedents and Outcomes of Retaliation against Whistleblowers: Gender Differences and Power Relationships. Organization Science, 19, 221-240. https://doi.org/10.1287/orsc. 1070.0310

[13] Lee, J.Y., Heilmann, S.G. and Near, J.P. (2004) Blowing the Whistle on Sexual Harassment: Test of a Model of Predictors and Outcomes. Human Relations, 57, 297-322. https://doi.org/10.1177/0018726704043273

[14] Mesmer-Magnus, J.R. and Viswesvaran, C. (2005) Whistleblowing in Organizations: An Examination of Correlates of Whistleblowing Intentions, Actions, and Retaliation. Journal of Business Ethics, 62, 277-297. https://doi.org/10.1007/s10551-005-0849-1 
[15] Bjørkelo, B., Einarsen, S. and Matthiesen, S.B. (2011) Predicting Proactive Behaviour at Work: Exploring the Role of Personality as an Antecedent of Whistleblowing Behaviour. Journal of Occupational \& Organizational Psychology, 83, 371-394. https://doi.org/10.1348/096317910X486385

[16] Macnab, B.R. and Worthley, R. (2008) Self-Efficacy as an Intrapersonal Predictor for Internal Whistleblowing: A Us and Canada Examination. Journal of Business Ethics, 79, 407-421. https://doi.org/10.1007/s10551-007-9407-3

[17] Miceli, M.P. and Near, J.P. (2002) What Makes Whistle-Blowers Effective? Three Field Studies. Human Relations, 55, 455-479.

https://doi.org/10.1177/0018726702055004463

[18] Treviño, L.K. and Weaver, G.R. (2001) Organizational Justice and Ethics Program "Follow-Through": Influences on Employees' Harmful and Helpful Behavior. Business Ethics Quarterly, 11, 651-671. https://doi.org/10.2307/3857765

[19] Alleyne, P., Charles-Soverall, W., Broome, T. and Pierce, A. (2017) Perceptions, Predictors and Consequences of Whistleblowing among Accounting Employees in Barbados. Meditari Accountancy Research, 25, MEDAR-09-2016-0080. https://doi.org/10.1108/MEDAR-09-2016-0080

[20] Dalton, D. and Radtke, R.R. (2013) The Joint Effects of Machiavellianism and Ethical Environment on Whistle-Blowing. Journal of Business Ethics, 117, 153-172. https://doi.org/10.1007/s10551-012-1517-X

[21] Gao, J., Greenberg, R. and Wong-On-Wing, B. (2014) Whistleblowing Intentions of Lower-Level Employees: The Effect of Reporting Channel, Bystanders, and Wrongdoer Power Status. Journal of Business Ethics, 126, 85-99. https://doi.org/10.1007/s10551-013-2008-4

[22] Kaptein, M. (2011) From Inaction to External Whistleblowing: The Influence of the Ethical Culture of Organizations on Employee Responses to Observed Wrongdoing. Social Science Electronic Publishing, 98, 513-530. https://doi.org/10.1007/s10551-010-0591-1

[23] Lewis, D. (2007) A Survey of Whistleblowing/Confidential Reporting Procedures Used by Persons Disclosure Act 1998. Communications Law, 12, 124-130.

[24] Stansbury, J.M. and Victor, B. (2009) Whistle-Blowing among Young Employees: A Life-Course Perspective. Journal of Business Ethics, 85, 281-299. https://doi.org/10.1007/s10551-008-9770-8

[25] Lee, G. and Fargher, N. (2013) Companies' Use of Whistle-Blowing to Detect Fraud: An Examination of Corporate Whistle-Blowing Policies. Journal of Business Ethics, 114, 283-295. https://doi.org/10.1007/s10551-012-1348-9

[26] Vandekerckhove, W. (2012) The Content of Whistleblowing Procedures: A Critical Review of Recent Official Guidelines. Journal of Business Ethics, 108, 253-264. https://doi.org/10.1007/s10551-011-1089-1

[27] Park, H., Blenkinsopp, J., Oktem, M.K. and Omurgonulsen, U. (2008) Cultural Orientation and Attitudes toward Different Forms of Whistleblowing: A Comparison of South Korea, Turkey, and the UK. Journal of Business Ethics, 82, 929-939. https://doi.org/10.1007/s10551-007-9603-1

[28] Sweeney, T.J.T. (2013) The Influence of Subjective Norms on Whistle-Blowing: A Cross-Cultural Investigation. Journal of Business Ethics, 112, 437-451. https://doi.org/10.1007/s10551-012-1270-1

[29] Skivenes, M. and Trygstad, S.C. (2010) When Whistle-Blowing Works: The Norwegian Case. Human Relations, 63, 1071-1097. https://doi.org/10.1177/0018726709353954 